\title{
Regionalization and spatial properties of Ceará State rainfall in northeast Brazil
}

\section{Cíntia Uvo}

Center for Weather Forecast and Climate Studies, National Institute for Space Research, Cachoeira Paulista, Brazil

\section{Ronny Berndtsson}

Department of Water Resources Engineering, Lund University, Lund, Sweden

\begin{abstract}
The overall daily rainfall pattern of Ceará for 19 years, 1974-1992, was analyzed in terms of physiography and atmospheric circulation. This information was used to suggest a regionalization of the state's rainfall into homogeneous areas. The three large-scale precipitation mechanisms (Intertropical Convergence Zone, cold fronts, and upper air vortices) interact and create a certain rainfall pattern over the state during different months. An example of this interaction is the opposite behavior that the northern and southern parts of the state tend to have when considering the amount of precipitation during the rainy season; That is, in general, large amounts of rain in the southern part of the state tend to be associated with small amounts of rain in the northern part and vice versa, as influenced by the opposite influence of the cold fronts and the upper air vortices. At the same time, the orographical influence enhances the precipitation in the northern part of the state and decreases precipitation in the central part of the state. The state could be divided into six homogeneous precipitation regions: (1) the northwestern part of the state, locally influenced by the mountain massif of Serra da Ibiapaba; (2)-(3) the northern and northeastern Ceará influenced locally by sea breeze and the slopes of the Serra de Baturité; (4)-(5) the central state, influenced by the Chapada do Apodi and the Serra de Uruburetama; and (6) the southern part of the state, influenced mostly by cold fronts and by the slopes of the Serra do Araripe.
\end{abstract}

\section{Introduction}

The Ceará State is located in northeastern Brazil approximately between $3^{\circ}-8^{\circ} \mathrm{S}$ and $37^{\circ}-42^{\circ} \mathrm{W}$. The area is densely populated and the economy is based mainly on subsistence rain-fed crop production. Large variability in both interannual and spatial rainfall, however, often leads to devastating suffering and occasional mass migration problems [Chung, 1982].

Because of the complex rainfall patterns, which have profound socioeconomic effects on the local states in northeastern Brazil, much effort has been devoted to understand the climate and atmospheric circulation of the region as a whole [Strang, 1972; Kousky, 1979; Moura and Shukla, 1981; Rao et al., 1993; Uvo et al., 1995]. These studies have, however, generally dealt with large-scale features which affect monthly or longer-period precipitation patterns. Very few studies have concentrated on physiographical effects of the larger-scale circulation and short-term rainfall anomalies. Ramos [1975] studied the

\footnotetext{
Now at the Department of Water Resource Engineering, Lund University, Lund, Sweden. (e-mail: cintia@aqua.tvrl.1th.se)

Copyright 1996 by the American Geophysical Union

Paper number 95JD03235.

0148-0227/96/95JD-03235\$05.00
}

southern part of the northeastern region of Brazil. To the authors' knowledge there are no other studies corresponding to daily rainfall variability for the northern part of the northeastern region of Brazil. This is in spite of the wide range of use in design and management this information has for, e.g., hydraulic structures and rain-fed cropping systems.

In view of the above the objective of this paper was to analyze the overall daily rainfall pattern of Ceará in terms of physiography and atmospheric circulation. We used this information to suggest a regionalization of the state's rainfall into homogeneous areas. Finally, we have given a characterization of the spatial properties of each homogeneous rainfall area regarding the local rainfall regime.

\section{Data and Methodology}

\subsection{Climatic Conditions}

The northern part of northeastern Brazil, which encompasses the Ceará State, has a semiarid climate with the wet season between January and June. Average annual rainfall for the state varies between $550 \mathrm{~mm}$ in the interior to in excess of $1600 \mathrm{~mm}$ along the Serra da Ibiapaba in the northwest (Figure 1). The interannual variability may, however, exceed $40 \%$ of the mean [Kousky, 1979].

In general, four mechanisms appear to govern the rainfall regime of the region: (1) El Niño-Southern Oscillation (ENSO) events; (2) Atlantic Ocean sea surface temperature, 

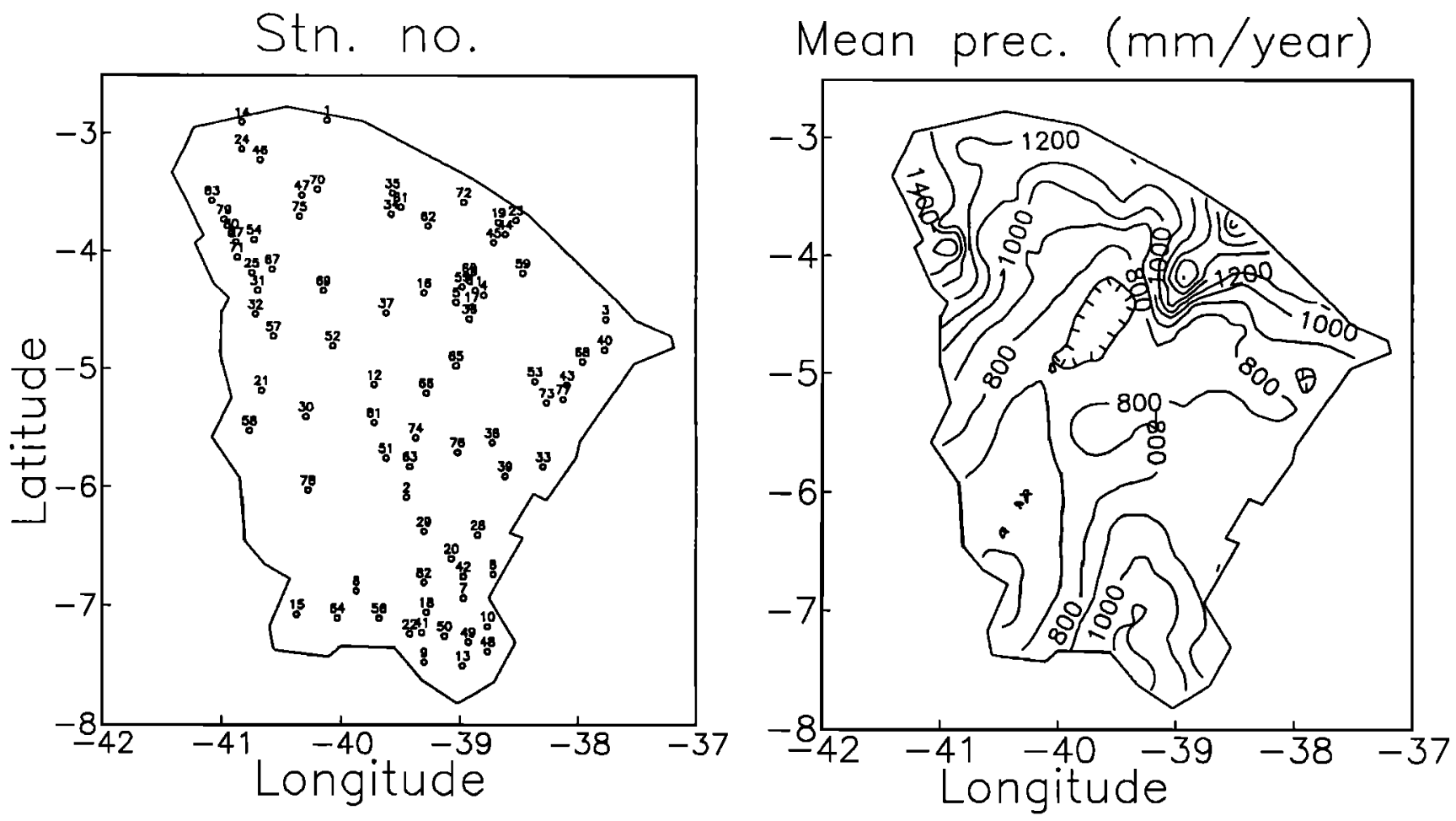

Figure 1. Locations of rainfall stations for data used in this study and mean annual rainfall in the Ceará State during the analyzed period 1974-1992 (hatched areas indicate local minima).

trade winds, and sea level pressure; (3) the Intertropical Convergence Zone (ITCZ) over the Atlantic Ocean; and (4) cold fronts and upper air vortices [Namias, 1972; Ratisbona, 1976; Markham and McLain, 1977; Hastenrath and Heller, 1977; Kousky, 1979; Moura and Shukla, 1981; Ropelewski and Halpert, 1987; Nobre and Molion, 1988; Uvo, 1989; Alves and Repelli, 1992; Uvo et al., 1995].

Rainfall during January and February is mainly dominated by cold fronts and/or their remnants [Kousky, 1979; Oliveira, 1986; Alves and Kayano, 1991]. However, also high-level tropical vortices, associated with the cold fronts, play an important role for the Ceará precipitation during these months [Kousky and Gan, 1981]. The cold fronts cause precipitation mainly in the southern part of the state, while the vortices are responsible for precipitation mostly in the northern part.

At the end of February to March the ITCZ over the tropical Atlantic Ocean reaches its southernmost position and thus generates the principal rainy season over the Northeast of Brazil (with a maximum of precipitation in March for Ceará) [Nobre and Molion, 1988; Uvo, 1989]. The precipitation caused by the ITCZ influences mostly the northern part of the state in February and then displaces southward during March. In April and May, a displacement northward is noted in the precipitation [Uvo et al., 1995]. However, also during February and March, High Level Tropical Vortices can continue to influence the rainfall pattern [INPE, 1992a, b, 1993a, b; FUNCEME, 1993]. When the ITCZ returns to its normal more northern position, the principal rainy season over the Northeast finishes [Uvo, 1989; Uvo and Nobre, 1989].

The topography of Ceará (Figure 2) greatly influences the above general rainfall-bearing mechanisms. This is seen in the annual mean rainfall pattern (Figure 1). Major topographical ridges along the state boundaries in the northwest (Serra da Ibiapaba) and south (Chapada do Araripe) are seen to enhance the rainfall greatly by orography. This is also seen for several smaller mountain peaks about $0.5^{\circ}-1.0^{\circ}$ south of the coastal line (e.g., the northernmost peak of the Serra de Baturite). The main parts of the Serra de Uruburetama in the interior of the state appear, however, to be located in a typical rain shadow. Ramos [1975], in a study of Petrolina to the south of Ceará, concluded that orographic effects probably are responsible for the morning rainfall maximum over the Petrolina valley system and for the afternoon rainfall over western elevated terrains. He speculated that this was due to the radiative cooling of the windward east slopes of the mountains during night, which generates downslope motion against the main easterly flow and convergence. The same mechanisms may be at hand for large valley systems in Ceará. An example of this may be the rainfall maximum that appears in the large depression between the Chapada do Apodi and the Serra de Uruburetama (Figure 1). This area receives on average 8-900 $\mathrm{mm}$ per year, while the elevated southwestern part of the Serra de Uruburetama receives less than $700 \mathrm{~mm}$.

In general, the coastal zones are areas with relatively large rainfall amounts. This probably reflects the main wind systems from the east that interact with the coastline during the rainy season [Rao et al., 1993]. Ramos [1975] noted that most rainfall systems move from east to west with a mean speed of $2^{\circ}-3^{\circ}$ longitude per day. Yamazaki and Rao [1977] also stressed the importance of westward propagating cloud systems during the winter maximum in the east coast of Northeast Brazil. Kousky [1980] argued that rainfall over eastern-northeastern Brazil occurs mostly during nighttime due to the formation of a convergence zone between the land breeze and the mean flow. 


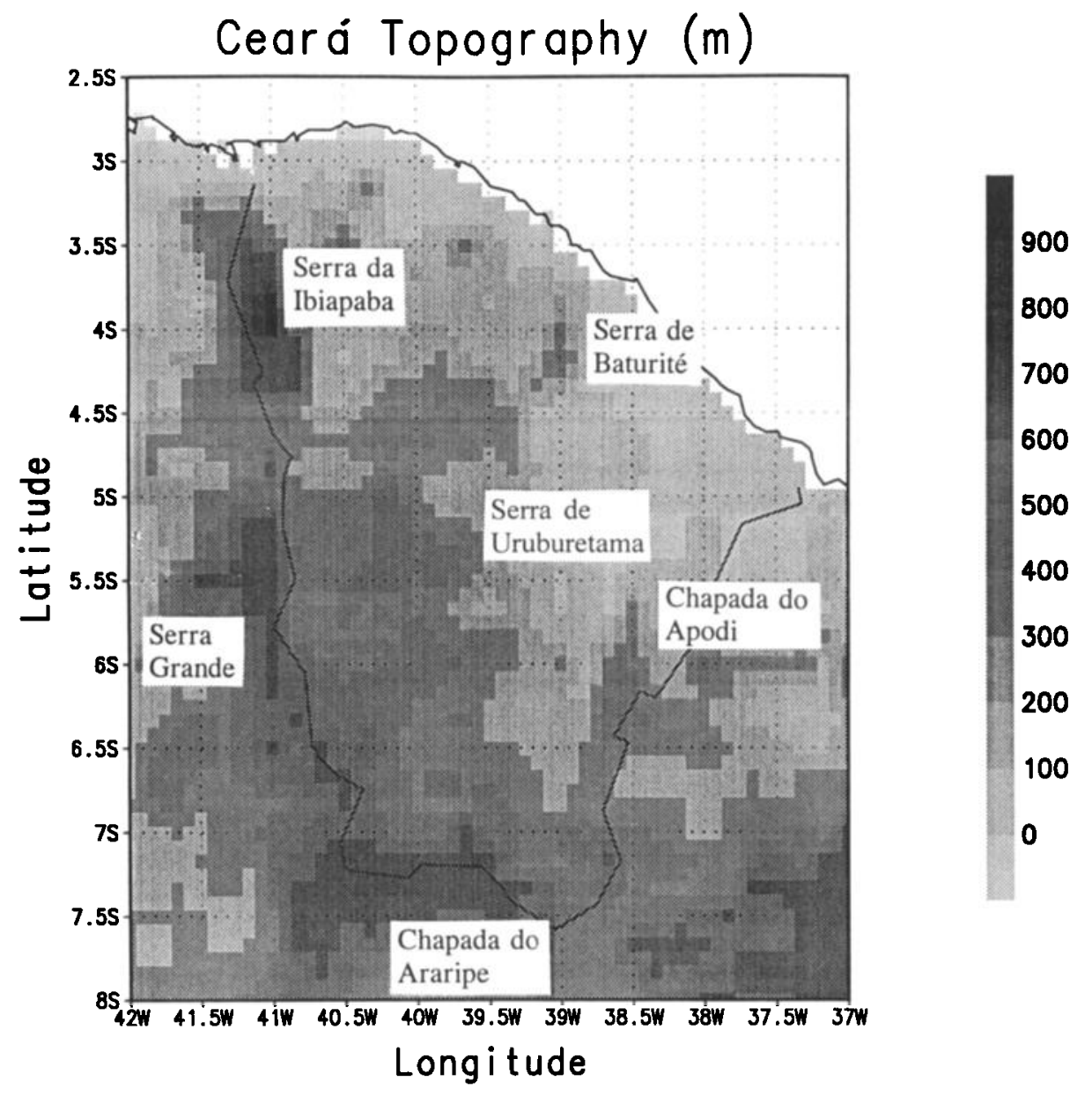

Figure 2. Topography of the Ceará State.

\subsection{Data}

The daily rainfall data used in this study were supplied by the Fundação Cearense de Meteorologia e Recursos Hídricos (FUNCEME) [Brito et al., 1991]. After a preliminary inspection of the database, 83 rainfall stations were selected according to Figure 1 . These stations were selected due to an even distribution over Ceará and because they had less than $10 \%$ missing data. The average of total missing data for the 83 selected stations was $5 \%$. The gaps in the data were exchanged by the daily mean for the 19-year analyzed period, 1974-1992.

The statistical analyses were performed on the base- 10 logarithm of daily data after exchanging a small value equal to 0.01 for the original zeros. This was done to transform the data to an approximately normal distribution to satisfy the prerequisites for the statistical analyses. A test equivalent to the Shapiro-Wilk test [Shapiro and Wilk, 1965] was used based on the correlation coefficient between the normal scores and the data. Results showed that the normal distribution could not be rejected at the significance level of $95 \%$ or greater for most of the stations. Only the data for December-July ( 8 months) were used since AugustNovember is the dry season and the data for this period mainly contain zeros.

\subsection{Methods}

Several multivariate analyses techniques were employed in this study to delineate spatial properties of daily rainfall. To find areas of high similarity regarding variance of rainfall time series, singular value decomposition (SVD) was used. The SVD utilizes the cross-covariance matrix between two data sets to identify pairs of spatial pattern that explain the maximum squared temporal covariance [Bretherton et al., 1992]. The SVD is a generalization of the diagonalization process used in principal component analysis (PCA) for square matrices. In our case the rainfall database was used to find maximum autocovariance. Consequently, the used rainfall data itself correspond to the two data sets for the cross-covariance matrix.

The output of the SVD may be homogeneous correlation maps or heterogeneous correlation maps. The first ones are defined as the vectors of correlation between the grid point values of one field and the $\mathbf{k}^{\text {th }}$ expansion coefficient of the same field. Heterogeneous correlation maps are the vectors of correlation between the grid point values of one field and the $\mathrm{k}^{\text {th }}$ expansion coefficient of the other field. In this second case, the maps indicate how well the grid points in one field can be predicted from the $\mathrm{k}^{\text {th }}$ expansion coefficient of the other field. In our case, as the rainfall matrix corresponds to 
the two data sets, the heterogeneous and homogeneous fields were the same. In this work, we show the results for the homogeneous correlation maps.

The squared covariance fraction (SCF), as described by Bretherton et al. [1992], was used to find the relative importance of each expansion mode in the SVD analysis. The $\mathrm{SCF}$, consequently, measures the percentage of variance that is explained by the corresponding principal components. To determine if local correlation coefficients differed significantly from what was expected due to chance, a test of the null hypothesis based on the Student's $t$ distribution was performed [Bendat and Piersol, 1986]. Shaded regions in subsequent figures indicated a significance level of $95 \%$ or greater.

The results of the SVD were checked and compared to corresponding calculations by empirical orthogonal functions (EOF). The theory of SVD and EOF is well discussed and compared with other multivariate techniques by Bretherton et al. [1992] and Wallace et al. [1992].

Results of the SVD analysis were rotated by use of the VARIMAX (orthogonal rotation) procedure [e.g., Richman, 1986]. This is the most commonly used rotation procedure [e.g., Bonell and Sumner, 1992].

Grouping of rainfall stations to find rainfall areas of high similarity was done by cluster analyses. For this the outcome of the SVD analysis was used (the homogeneous correlation maps). This is one of the means that has been developed for grouping variables into subsets that are linearly related to each other. Cluster analysis methods are used to develop dendograms that are treelike hierarchical diagrams that show the relations among all variables in a given set [Krumbein and Graybill, 1965]. The correlation matrix was used as a basis for discerning the levels of the relationship that occurred among the variables. Thus one or more pairs of the attributes are selected for being highly correlated, and linkages are computed between these pairs and the remaining variables to develop a hierarchy of the interrelations that shows the levels of the linkage in the set of data. It is a common practice to use orthogonal solutions as input for the cluster analyses. In our case, only the components that explained most of the variance of the rainfall and that were physically explainable were kept for the cluster analysis. Different varieties of clustering techniques were tested (e.g., centroid, median, and Ward). The Ward method was shown to give regions that could be given the most consistent physical explanation. The Ward method is a commonly used method which is based on mutually exclusive subsets and does not assume normality [e.g., Cox, 1957; Bonell and Sumner, 1992].

The rainfall regions identified in the above methodology were further analyzed by investigation of the spatial correlation pattern. The spatial correlation function gives a quantitative measure of the rainfall variability within the investigated area. Thus it can be used to interpolate the properties to points where observations are not available, estimating spatial averages from discrete observations, and for defining new stations where observations are the most efficient. The spatial correlation between gages $z_{1}$ and $z_{2}$ for time series of rainfall was calculated as

$$
r_{z_{1}, z_{2}, t}=\frac{\operatorname{cov}\left(R_{z_{1}, t}, R_{z_{2}, t}\right)}{\left[\operatorname{var}\left(R_{z_{1}}, t\right) \operatorname{var}\left(R_{z_{2}, t}\right)\right]^{1 / 2}}
$$

where $r_{z_{1}, z_{2}, t}$ is the correlation coefficient between points $z_{1}$ and $z_{2}$ for time $t ; R_{z_{1}, t}$ is rainfall at point $z_{1}$ for time $t ; R_{z_{2}, t}$ is rainfall at point $z_{2}$ for time $t$.

If second-order stationarity (both mean and variance are independent of spatial location) is assumed for the observations, the correlation can be expressed in a general way as a function of distance $(h)$ and direction $(\Phi)$ according to

$$
r_{h, \Phi, l}=r_{z_{1}, z_{2}, l}
$$

The correlation $r_{h_{1} \Phi_{l}}$ may be plotted either depending on distance only or depending on both distance and direction. If the spatial correlation function is isotropic, the correlationdistance diagram contains all necessary information. Otherwise, the correlation function is nonisotropic and the directional information needs to be included.

\section{SVD Analysis}

Figure 3 shows the homogeneous correlation maps for the first four modes in the SVD expansion for daily data during 1974-1992. In this case, as mentioned before, the two matrices considered for the SVD calculation were the same precipitation database. Only the first two modes were statistically significant. However, since the third and fourth mode could be given physical interpretations, they were kept for further analyses. Also, the first mode (corresponding to the mean rainfall) was removed and the time series corresponding to the remaining variance were reconstructed and reanalyzed. This showed that the new squared covariance fractions (SCF) increased to $33.3 \%, 7.3 \%$, and $6.6 \%$, for the second, third, and fourth modes shown in Figure 3, respectively. Consequently, when removing the variance corresponding to the mean, several secondary modes became significant. To consider the variation not only caused by the mean value, these secondary modes (up to the fourth mode) were kept for further analyses.

The first mode in Figure 3 mainly corresponds to mean rainfall as mentioned above, essentially caused by the influence of the Intertropical Convergence Zone over the Atlantic, upper air vortices, and cold fronts [Satyamurty and Nobre,1995], which in turn also are related to topography. This is clearly seen when comparing the first mode in Figure 3 with Figures 1 and 2 . All correlations are statistically significant at the $95 \%$ probability level. The SCF is $92.7 \%$, indicating that almost all the variance is described by the first mode.

The second mode explained only $2.4 \%$ of the variance. However, the correlations were significant in two distinct areas, one large area to the south and one smaller area to the north. The northern area has negative correlations, while the southern area has positive correlations indicating a reverse relationship. Most likely, the spatial pattern to the south for this mode is connected to frontal characteristics during the local summer period. This is seen in Figure 4 which shows homogeneous correlation maps for the second mode during December to June. During December there is no indication of frontal activities. Instead, the pattern indicates effects of local convection and topography. In January this pattern is greatly modified similar to the annual map in Figure 3, indicating frontal progress from the south. In February this pattern is further enhanced and the correlation reaches a maximum 

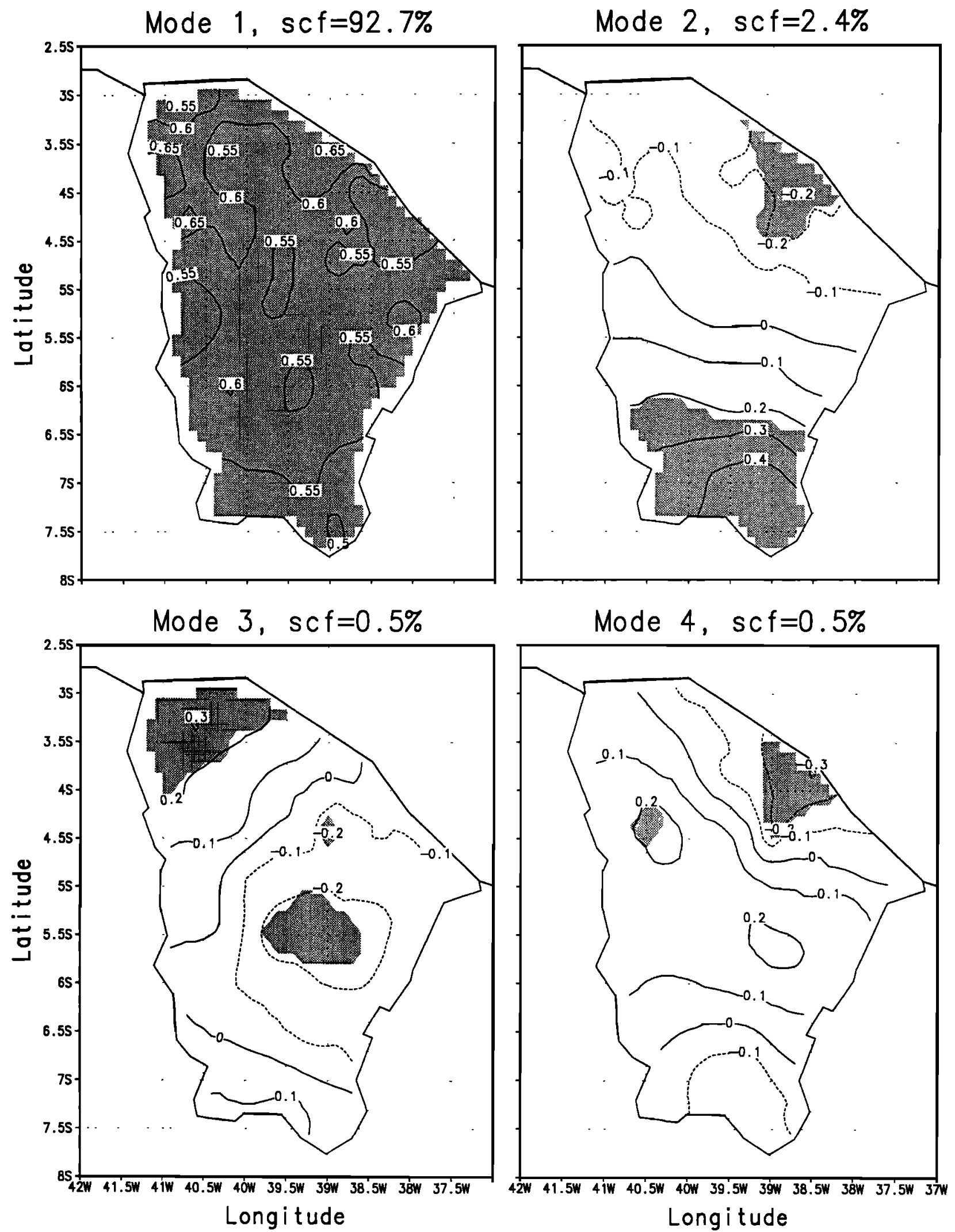

Figure 3. Homogeneous correlation maps for the first four modes in the singular value decomposition (SVD) expansion for daily data during 1974-1992 (SCF, squared covariance fraction; shading indicates significance at or above the $95 \%$ level; dashed contours indicate negative correlations). 

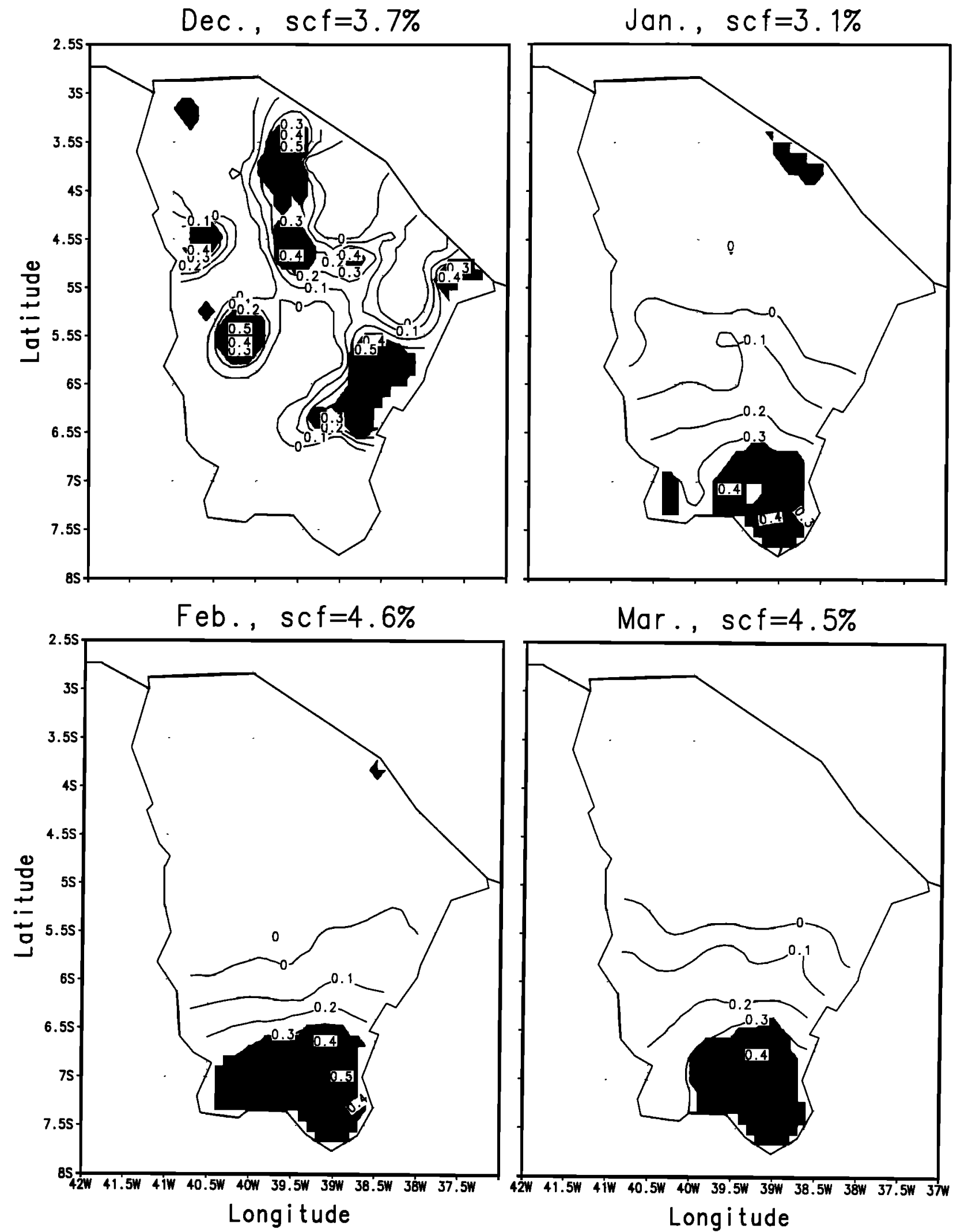

Figure 4. Homogeneous correlation maps for the second mode during December to June (shading indicates significance at or above the $95 \%$ level). 

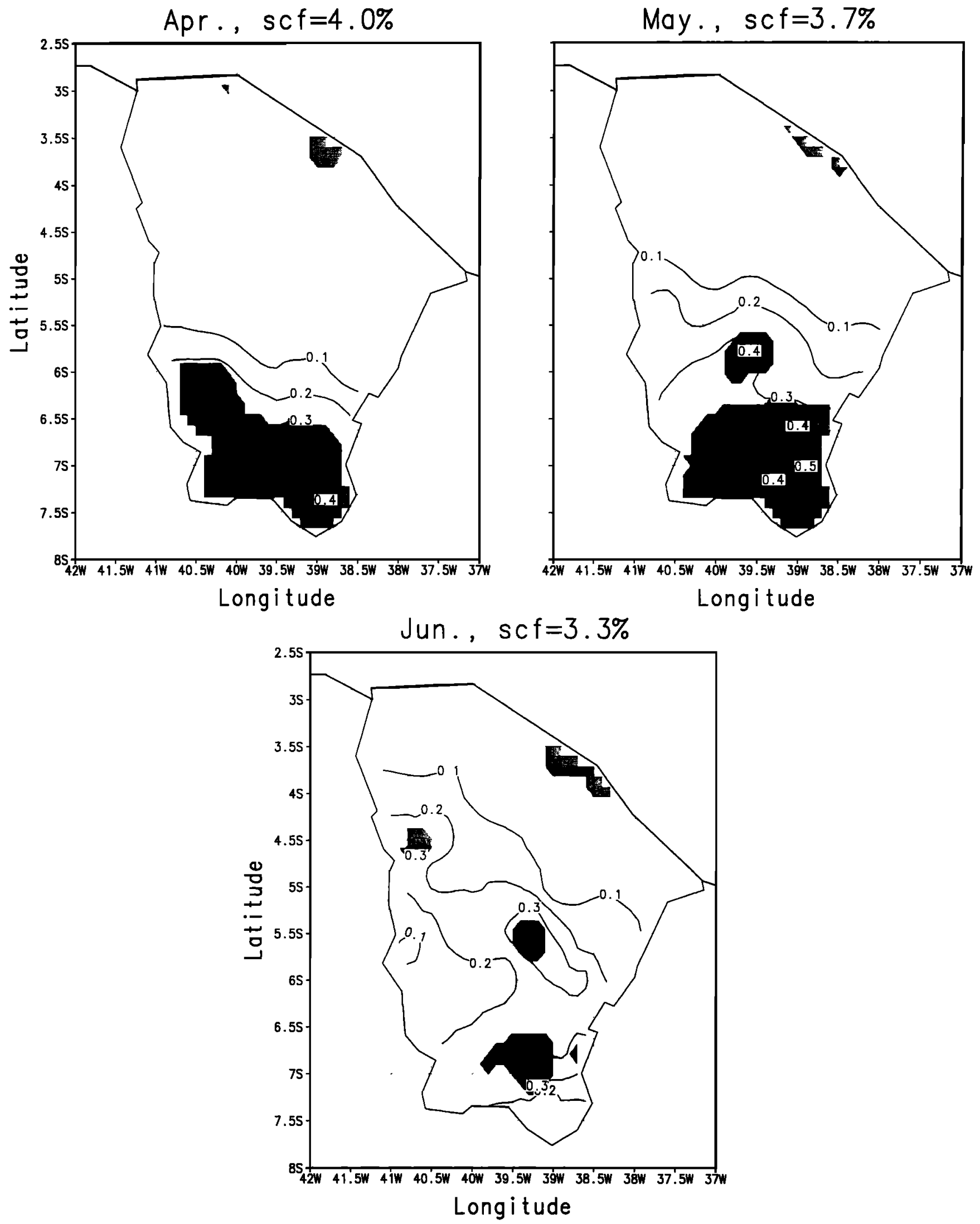

Figure 4. (continued) 
value of 0.5 (Figure 4). Succeeding months display a continuous decrease in correlation and, finally, in June (Figure 4) the pattern again resembles the one for December with no evidence of frontal pattern.

Consequently, the temporal pattern of the second mode corroborates the results of Kousky [1979] and Oliveira [1986] that rainfall in Ceará is mainly dominated by cold fronts in January and February. According to the pattern of the second mode in the SVD analysis, effects of cold fronts progressing from the south may, in general, affect the rainfall pattern in Ceará south of $6^{\circ} \mathrm{S}$ (Figure 4). January and February are months when the passage of cold fronts has greatest effects. According to Figure 4, however, there appears also to be an opposite behavior on precipitation when comparing the northern part of the state, close to the peaks of Serra de Baturité, and the southern part. The pattern shown in Figure 4 indicates that when there is no frontal activity in the south, there is a probability of rain in the northern parts of Serra de Baturité along the coastline. This opposite behavior may be explained by cold fronts reaching southern Ceará, influencing also the northern regions. Frequently, this influence is related to the presence of an upper air cyclonic vortex that is common in this time of year. The upper air cyclonic vortices are generated by cold fronts over the climatological trough that appears over Northeast Brazil during the summer period. Typically, these vortices have a subsidence area in their center and a convective band northward and westward around their centers. If the cold fronts do not reach lower latitudes, the convective boundary of the vortex brings convection to northern Ceará, while the southern part of the state is influenced by the center of the vortex. Also, the lack of cold fronts and vortices allows ITCZ activity over the northern part of Ceará State.

The third mode explained only $0.5 \%$ of the total variance (7.3\% when removing the first mode's variance) but still has two main areas with significant correlations. The area located to the northwest in Figure 3 is an orographic effect related to the sloping topography of the Serra de Ibiapaba interacting with the mean atmospheric flux of the region (trade winds). An evidence of this system is the substantial increase in mean annual rainfall in the depression northeast of Serra de Ibiapaba. The second area in the interior of Ceará is located in large valley systems separated by relatively high mountain ridges between Serra de Baturité and Chapada do Apodi. This area may develop a type of valley rainfall due to radiative cooling of the windward east slopes of the mountains during night, as noted by Ramos [1975]. Evidence of this is the rainfall maximum for mean annual rainfall, that appears west of the Chapada do Apodi (Figures 1 and 2).

The fourth mode, similarly as the third mode, only explained $0.5 \%$ of the total variance. However, when the first mode was removed, it explained $6.6 \%$. The area of high correlations is located along the coastline and around the northernmost peaks of Serra de Baturité. Consequently, the fourth mode displays the coastal influence on rainfall over Ceará and the sea breeze effect along the coastline.

The four modes described above were included in the clustering analyses. By use of the VARIMAX criteria, however, annual and monthly SVD maps were rotated to investigate if simplified physically explainable structures could be attained. This was, however, not the case. Instead, the first mode (corresponding to mean value) appeared to mix with the other modes, resulting in correlation maps that could not be interpreted in any reasonable way. Figure 5 shows an example of how the total variance (SCF) was fractionated among the four first modes, over the different months for the nonrotated and the rotated time series.

The SVD analysis was compared to a corresponding empirical orthogonal function (EOF) analysis (not shown). As expected, results were similar for all analyzed modes and the same physical characteristics could be observed.

\section{Cluster Analysis}

As mentioned above, the first four modes of the nonrotated SVD could be given physical explanation of the rainfall climate over Ceará and these modes were, consequently, included in the cluster analysis. A cluster analysis can be said to be a standard methodology to consider the results from the SVD [Bonell and Sumner,1992]. Figure 6 shows the cluster dendrogram for nonrotated SVD maps using the Ward method. Several clustering methods (centroid and median) using various sets of the modes (e.g., mode 1 , mode 1 plus mode 2 , etc.) were investigated to analyze the effects on the resulting regionalization. However, Ward's method and using all four modes appeared to give the most reasonable and physically explainable regions.

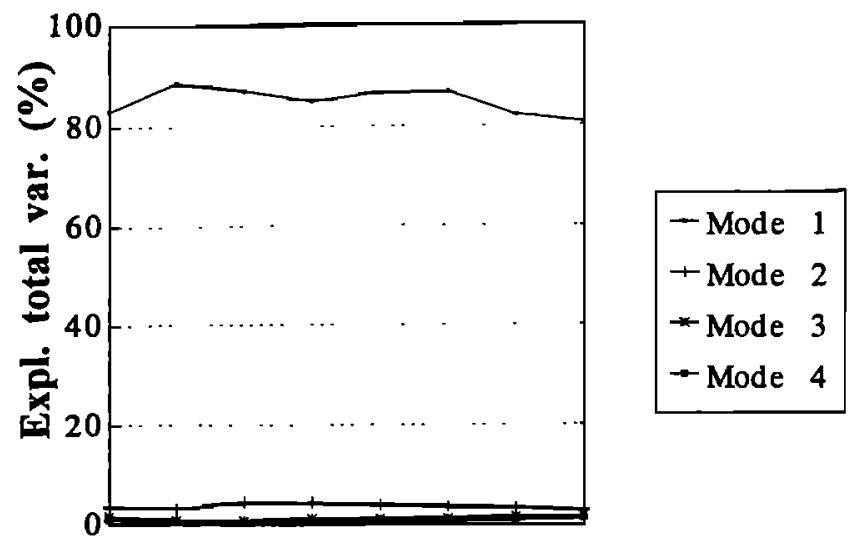

(a)

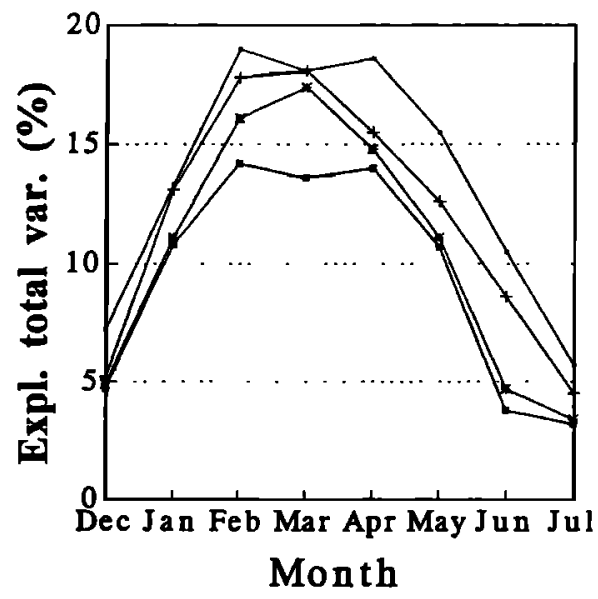

(b)

Figure 5. Explained total variance (SCF) for (a) nonrotated and (b) VARIMAX rotated monthly rainfall. 


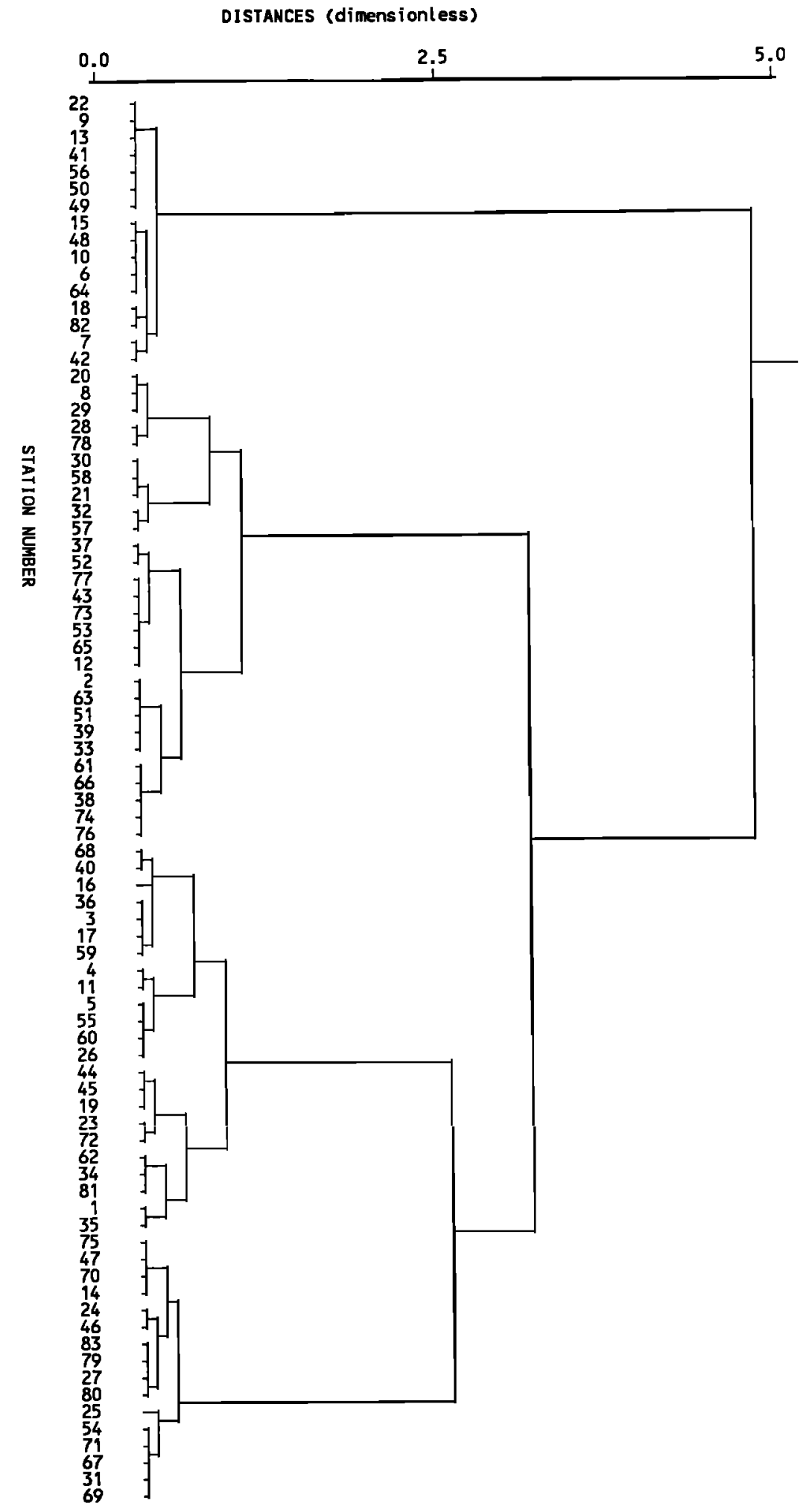

Figure 6. Cluster dendrogram for nonrotated SVD maps using the Ward method.

Figure 7 shows the resulting rainfall regions, depending on the level of detail in the cluster dendrogram in Figure 6 . The emerging regions can thus be used depending on the necessary level of detail. For example, a hydrological regionalization would require a division into smaller subregions (level 3), while for a meteorological regionalization, it would probably be sufficient with larger subregions (levels 1-2).

Level 1 in Figure 7 contains four major regions. Each of these regions displays a rainfall climate that is governed by different main mechanisms. The large region to the northwest is an area which is much influenced by the mountain massive 

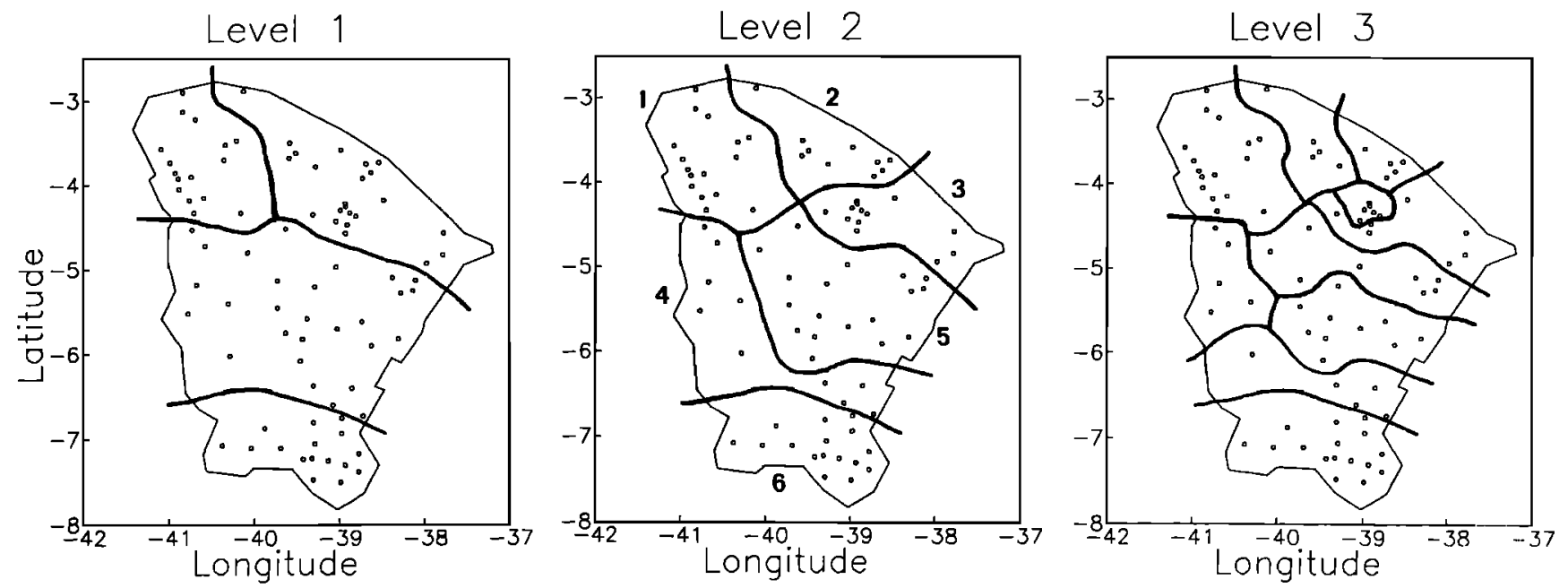

Figure 7. Rainfall regions, depending on level of detail in the cluster dendrogram in Figure 6.

Serra da Ibiapaba. As mentioned previously, there is a pronounced orographic effect along the slopes of Serra da Ibiapaba .

The coastal region to the northeast is mainly dominated by the Intertropical Convergence Zone [Uvo et al., 1995]. Also, the formation of a convergence zone between the land breeze and the mean flow may influence the rainfall climate in this region [Kousky, 1980]. The local topography of the peaks of the Serra de Baturité, however, also greatly influences the local rainfall pattern.

The third region encompasses the large arid inland area of Ceará. The area is partly located in an enormous rain shadow behind the Serra de Baturité and the Serra de Uruburetama. The main rainfall mechanisms appear to be a valley phenomenon west of the Chapada do Apodi and occasional fronts or upper air vortex boundary that may reach up into this region. All these three previous regions are highly influenced by the presence of the Intertropical Convergency Zone over the Atlantic.
The fourth region contains the southernmost area of the state. This area is mainly influenced by fronts coming from the south. The topography and outskirts of the Chapada do Araripe, however, also modify the local rainfall pattern.

When increasing the level of detail (level 2 in Figure 7), four new subregions emerged. A pair of these (regions 2-3 in Figure 7) appeared due to the topographical effects of the northernmost peaks of the Serra de Baturite. The second pair of subregions (regions 4-5 in Figure 7) emerged over the large valley system between Serra de Uruburetama and Chapada do Apodi described previously. Increasing the level of detail further (level 3 in Figure 7) displayed further details of mostly local topographical effects.

\section{Spatial Correlation Analysis}

A spatial correlation analysis was performed as described in section 2.3. The regionalization level 2 , according to Figure 7, was considered appropriate for this analysis since

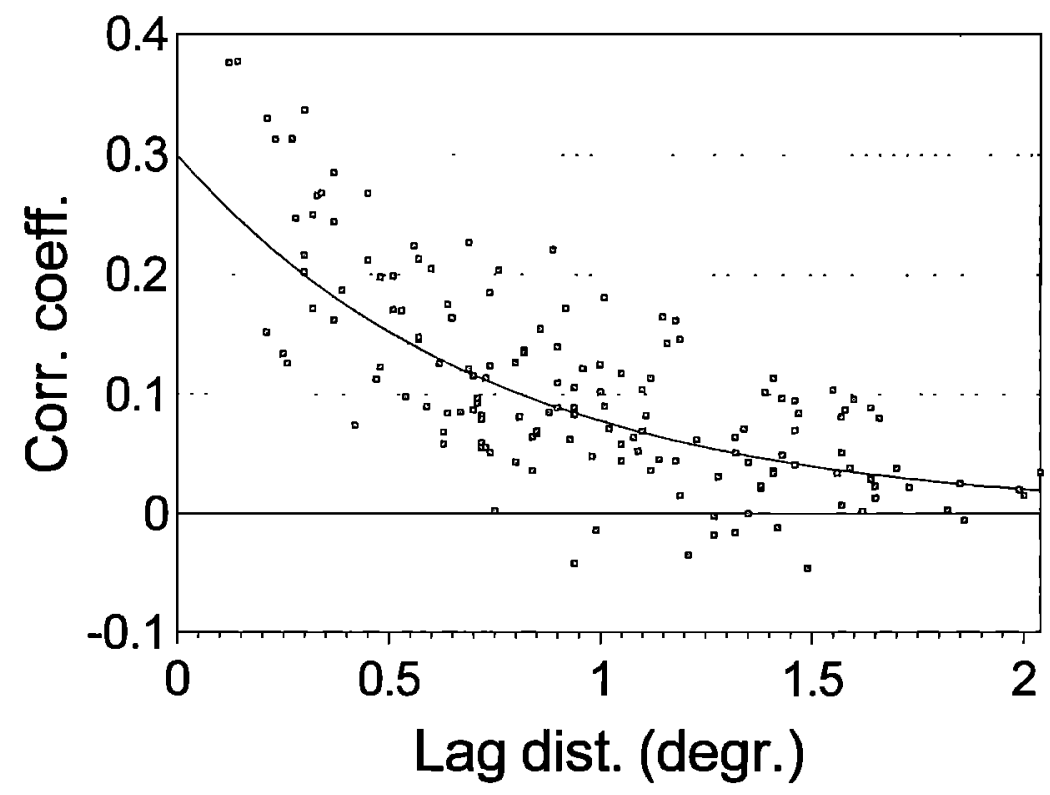

Figure 8. Correlation depending on interstation distance for region 5 (regionalization level 2) in Figure 7. Solid line has been fitted by regression. 
the subgrouping considers the main rainfall mechanisms of the area. The regions numbered consecutively from 1 to 6 in Figure 7 were assumed to be homogeneous and were used in the spatial correlation analysis.

Figure 8 shows an example of the correlation $r_{h, \Phi} \Phi_{l}$ plotted depending on distance only for region 5 in Figure 7 . A clear distance dependence is noted. Even for small interstation distances, a relatively small correlation coefficient is noted, which indicates a large spatial variability. A large scatter, however, is also displayed for correlation coefficients calculated for combined stations with the same interstation distance. This indicates that the spatial correlation function is nonisotropic and the directional information needs to be included.
Figure 9 shows the spatial correlation functions $r_{h, \Phi_{,} \text {, }}$ including the directional information. It is obvious from the figure that the spatial correlation is typically nonisotropic and varying, depending on the different regions. The correlation structure is typically elongated depending on the influence of local topography and/or coastal line. The effects of local topography is exemplified by the correlation structure in region 3 . In general, correlation isolines of daily rainfall may be expected to run parallel to the coastline [Berndtsson, 1988]. This is also the case for the correlation pattern of region 2 (Figure 9). In region 3 , however, this general pattern is greatly modified by the northernmost peaks of the Serra de Baturité, which forces the correlation isolines to become perpendicular to the coastline. In general, the three coastal
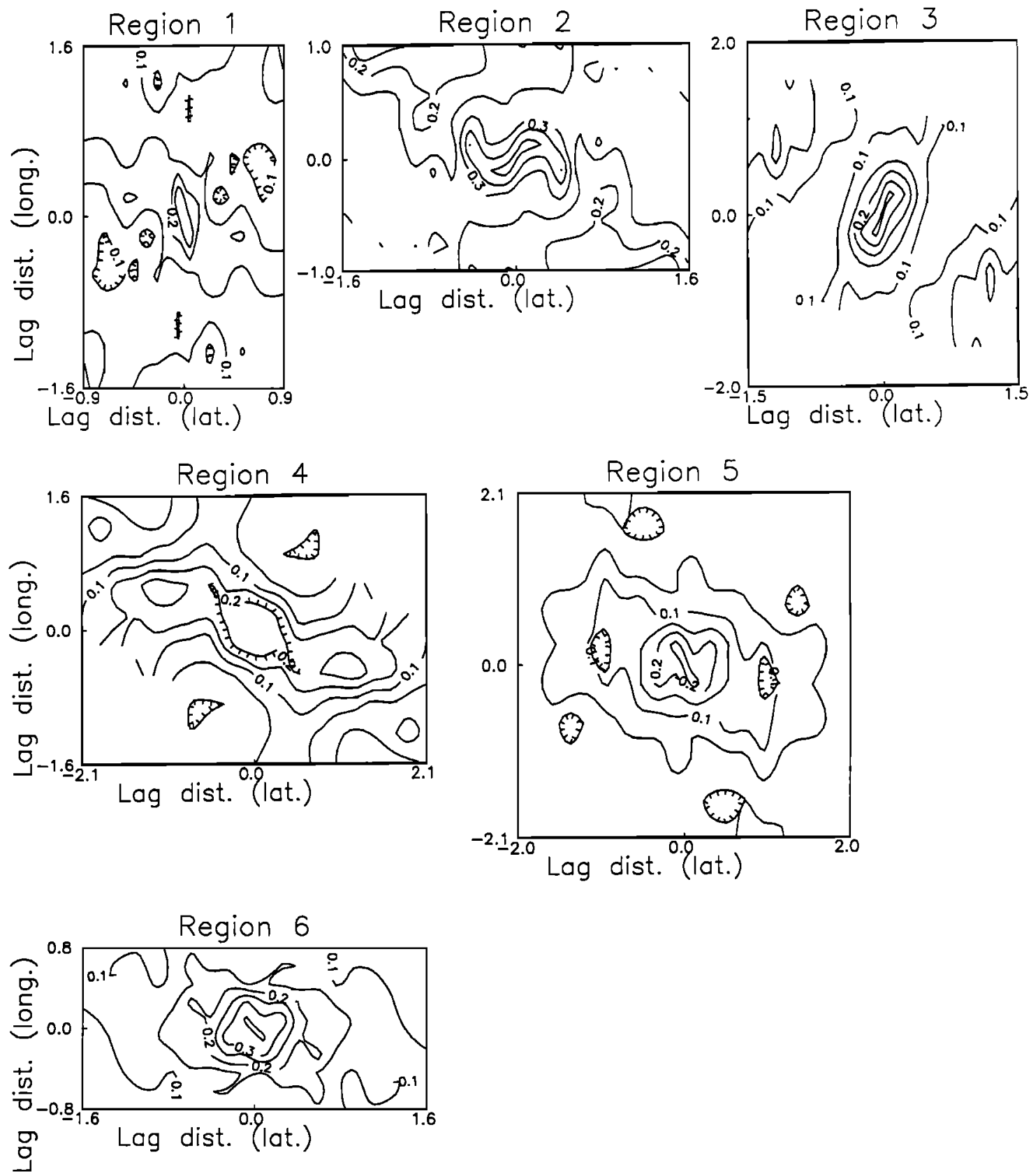

Figure 9. Spatial correlation structures for regionalization level 2 in Figure 7 (hatched areas indicate local minima). 
regions display a more complicated (nonisotropic) correlation structure compared to the three inland regions. This may be an effect of different rainfall mechanisms during different parts of the year and/or coinciding effects of sea breeze and topography.

\section{Summary and Conclusions}

The overall daily rainfall pattern of Ceará State in Brazil was analyzed in terms of physiography and atmospheric circulation. The analyses displayed how large-scale and synoptic scale rainfall over Ceará State (ITCZ, cold fronts, and upper air vortices) are influenced by local orography to create a nonhomogeneous distribution of precipitation over the state. The three large-scale precipitation mechanisms interact and establish a certain rainfall pattern over the state during different months. An example of this is the northern and southern parts of the state that tend to have an opposite behavior when considering the amount of precipitation during the rainy season; that is, in general, large amounts of rain in the southern part of the state tend to be associated with small amounts of rain in the northern part and vice versa, as influenced by the opposite influence of the cold fronts and the upper air vortices. These results were clearly seen when analysing the structures of the homogeneous maps from the SVD analyis. At the same time, the orographical influence enhances the precipitation in the northern part of the state and decreases precipitation in the central part of the state.

A regionalization of the state's rainfall was made into homogeneous regions by use of multivariate methods (SVD and Cluster analysis). Results showed that the Ceará State can be divided into six homogeneous precipitation regions: (1) the northwestern part of the state, locally influenced by the mountain massif of Serra de Ibiapaba; (2)-(3) the northern and northeastern Ceará influenced locally by the sea breeze and the slopes of the Serra de Baturite; (4)-(5) the central state, influenced be the Chapada do Apodi and the Serra de Uruburetama; and (6) the southern part of the state, influenced mostly by the cold fronts and by the slopes of the Serra do Araripe.

Acknowledgments. This study was performed during a guest research period (RoB) at the National Institute for Space Research, São José dos Campos, Brazil. The guest research period was supported by the Swedish Institute. The Swedish Natural Science Research Council funded part of the study. The study was finalized during a guest research period of C. Uvo at the Department of Water Resources Eng., Lund University, Sweden also sponsored by the Swedish Institute. The Fundação Cearense de Meteorologia e Recursos Hidricos (FUNCEME) supplied the data for this study. This support is gratefully acknowledged.

\section{References}

Alves, J. M. B., and M. T. Kayano, Preliminary studies of the precipitation in south Ceará during the pre-rainy season.(in Portuguese), Climanal. Bull. 6(4), 41-50, 1991. (Available from Inst. Nac. de Pesq. Espaciais, São José dos Campos, São Paulo, Brazil)

Alves, J. M. B., and C. A. Repelli, The precipitation variability on north-northeast Brazil and the El Niño-Southern Oscillation events, Rev. Brasil. Meteorol., 7, 583-592, 1992.

Bendat, J. S., and A. G. Piersol, Random Data - Analysis and Measurement Procedures, 525 pp., John Wiley, New York, 1986.

Bonell, M., and G. Sumner, Autumn and winter daily precipitation areas in Wales, 1982-1983 to 1986-1987, Int. J. Climatol., 12, 77-102, 1992.
Berndtsson, R., Temporal variability in spatial correlation of daily rainfall, Water Resour. Res., 24, 1511-1517, 1988.

Bretherton, C. S., C. Smith, and J. M. Wallace, An intercomparison of methods for finding coupled patterns on climate data, J. Clim., $5,541-560,1992$.

Brito, J. I. B., C. A. Nobre, and A. R. Zaranza, A precipitação da pré-estação e a previsibilidade da estação chuvosa do Norte do Nordeste. Climanal. Bull., 6(6), 39-54, 1991. (Available from Inst. Nac. de Pesq. Espaciais, São José dos Campos, São Paulo, Brazil)

Chung, J. C., Correlations between the tropical Atlantic trade winds and precipitation in Northeastern Brazil, J. Climatol., 2, 35-46, 1982.

Cox, D. R., Note of grouping, J. Am. Stat. Assoc., 52, 543-547, 1957.

Fundação Cearense de Meteorologia e Recursos HídricosFUNCEME, Sistemas sinóticos atuantes no nordeste do Brasil, Monit. Climat., 7(3), 1-3, 1993. (in Portuguese)

Hastenrath, S., and L. Heller, Dynamics of climate hazards in Northeast Brazil, Q. J. R. Meteorol. Soc., 103, 77-92, 1977.

Instituto Nacional de Pesquisas Espaciais-INPE, Vórtices Ciclônicos e Cavados, Climanal. Bull, 7(2), 10-12, 1992a. (in Portuguese)

Instituto Nacional de Pesquisas Espaciais-INPE, Vórtices Cíclônicos e Cavados, Climanal. Bull., 7(3), 9-12, 1992b. (in Portuguese)

Instituto Nacional de Pesquisas Espaciais-INPE, Vórtices Ciclônicos e Cavados, Climanal. Bull., 8(2), 26-28, 1993a. (in Portuguese)

Instituto Nacional de Pesquisas Espaciais-INPE, Vórtices Ciclônicos e Cavados, Climanal. Bull., 8(3), 13-14, 1993b. (in Portuguese)

Kousky, V. E., Frontal influences on Northeast Brazil, Mon. Weather. Rev., 107, 1140-1153, 1979.

Kousky, V.E., Diurnal rainfall variation in Northeast Brazil, Mon. Weather. Rev., 108, 488-498, 1980.

Kousky, V. E., and M. A. Gan, Upper tropospheric cyclonic vortices in the tropical South Atlantic, Tellus, 33, 539-551, 1981.

Krumbein, W.C., and F.A. Graybill, An Introduction to Statistical Models in Geology, McGraw-Hill, New York. 1965.

Markham, C. G., and D. R. McLain, Sea surface temperatures related to rain in Ceará, northeastern Brazil, Nature, 265, 320$323,1977$.

Moura, A. D., and J. Shukla, On the dynamics of droughts in Northeast Brazil: Observations, theory, and numerical experiments with a general circulation model, J. Atmos. Sci., 38, 2653-2675, 1981.

Namias, J., Influence of northern hemisphere general circulation on drought in Northeast Brazil, Tellus, 24, 336-343, 1972.

Nobre, C.A., and L.C.B. Molion, The climatology of droughts and drought prediction. in The Impact of Climatic Variations on Agriculture, vol. 2, Assessments in Semi-Arid Regions, edited by M. Parry, T. R. Carter, N. T. Konijn, Kluwer Acad., Norwell, Mass., 1988.

Oliveira, A.S., Interactions between frontal systems in South America and convection over Amazonia (in Portuguese), INPE4008-TDL/239, 1986. (Available from Inst. Nac. de Pesq. Espaciais, São José dos Campos, São Paulo, Brazil)

Ramos, R. P. L., Precipitation characteristics in the Northeast Brazil dry region, J. Geophys. Res., 80, 1665-1678, 1975.

Rao, V. B., M. C. de Lima, and S. H. Franchito, Seasonal and interannual variations of rainfall over eastern Northeast Brazil, $J$. Clim., 6, 1754-1763, 1993.

Ratisbona, C.R., The Climate of Brazil, Climates of Central and South America, in World Survey of Climatology, vol. 12, edited by W. Schwerdtfeger and H.E. Landsberg, pp. 219-293, Elsevier, New York, 1976.

Richman, M. B., Rotation of principal components, J. Climatol., 6, 293-335, 1986.

Ropelewski, C. F., and M. Halpert, Global and regional scale precipitation patterns associated with the El Nino/Southern oscillation, Mon. Weather. Rev., 115, 1606-1626, 1987.

Satyamurty, P. and C. A. Nobre. Section on South America, in Monograph on the Southern Hemisferic Meteorology, edited by D. G. Vincent, in press, 1995.

Shapiro, S. S., and M. B. Wilk, An analysis of variance test for normality (complete samples), Biometrika, 52, 591-611, 1965.

Strang, D. M. G., Climatological analysis of rainfall normals in northeastern Brazil, (in Portuguese) $I A E-M-02 / 72.70 \mathrm{pp} ., 1972$ (Available from Cent. Tec. Aerospacial, São José dos Campos, São Paulo, Brazil) 
Uvo, C. R. B., The Intertropical Convergence Zone and its relationship with the precipitation over north-northeast region of Brazil, (in Portuguese) INPE-4887-TDL/378, 1989. (Available from Inst. Nac. de Pesq. Espaciais, São José dos Campos, São Paulo, Brazil)

Uvo, C. R. B., and C. A. Nobre, The Intertropical Convergence Zone (ITCZ) and the precipitation over north-northeast Brazil. Part I: ITCZ's position over equatorial Atlantic. (in Portuguese), Climanal. Bull., 4(7), 34-40, 1989. (Available from Inst. Nac. de Pesq. Espaciais, São José dos Campos, São Paulo, Brazil)

Uvo, C. R. B., C. A. Repelli, S. E. Zebiak, and Y. Kushnir, The influence of tropical Pacific and Atlantic SST on Northeast Brazil monthly precipitation, J. Clim., in press, 1995.

Wallace, J. M., C. Smith, and S. Bretherton, Singular value decomposition of wintertime sea surface temperature and $500 \mathrm{mb}$ heights anomalies, J. Clim., 5, 561-576, 1992.

Yamazaki, Y., and V.B. Rao, Tropical cloudiness over the South Atlantic Ocean, J. Meteorol. Soc. Jpn., 55, 205-207, 1977.

R. Berndtsson, Department of Water Resource Engineering, Lund University, Lund, Sweden. (e-mail: Ronny.Berndtssonetvrl. lth.se)

C. B. Uvo, Center of Weather Forecast and Climate Studies, National Institute for Space Research, Cachoeira Paulista, São Paulo, Brazil.

(Received March 9, 1995; revised December 2, 1995; accepted December 2, 1995.) 